\title{
The City as Perpetual Beta: Fostering Systemic Urban Acupuncture
}

\author{
Joel Fredericks, Glenda Amayo Caldwell, Marcus Foth and Martin Tomitsch
}

\begin{abstract}
Applying the concept of perpetual beta to cities proposes a continual and never complete process of city-making. Building on this notion, this chapter employs a conceptual framework of urban acupuncture for conducting and analysing localised small-scale community engagement activities through situated pop-up interventions. Pop-up interventions 'hack' public space by temporarily changing the feel of a place to promote awareness around civic issues. We argue that the use of situated popup interventions has the potential to provide more inclusive forms of community engagement by combining digital and physical media. The proposed framework employs pop-up activism to facilitate a middle-out approach that encourages citizens to actively identify topics for discussion. Two pop-up interventions in different locations in Australia are discussed in the chapter to assess in what way a systemic level of impact can arise from different processes of city hacking that are facilitated through a distributed, decentralised, yet concerted and regular local approach. We argue that a concerted process of implementing small urban interventions can contribute to an ongoing commitment to participatory city-making. Further work will show how each local intervention can contribute to translating the notion of perpetual beta into systemic change beyond the boundaries of their individual locale and - taken together-across different urban environments of the city.
\end{abstract}

\footnotetext{
J. Fredericks $(\bowtie)$

School of Software, Faculty of Engineering and IT,

University of Technology Sydney, Ultimo, Australia

e-mail: joel.fredericks@uts.edu.au
}

G. A. Caldwell $\cdot$ M. Foth

Urban Informatics Research Lab, Queensland University of Technology, Brisbane, Australia e-mail: g.caldwell@qut.edu.au

M. Foth

e-mail:m.foth@qut.edu.au

M. Tomitsch

Design Lab, Sydney School of Architecture Design and Planning, The University of Sydney, Sydney, NSW 2006, Australia

e-mail: martin.tomitsch@sydney.edu.au 
Keywords Perpetual beta $\cdot$ Urban acupuncture $\cdot$ Community engagement Middle-out design $\cdot$ Pop-up interventions $\cdot$ Systemic change $\cdot$ Australia

\section{Introduction}

Humanity faces many challenges in both the natural and the built environment. Cities struggle with increased pressure on urban infrastructures and housing caused by population growth, lack of public transport options and more frequent natural disasters triggered by climate change. At the same time, citizens have more opportunities than ever to be involved in the planning, design and decision-making process of citymaking. Often seen as only a formality, local governments undertake community engagement processes to ask citizens about policy change and proposed infrastructure developments. This top-down approach generally 'informs' citizens only rather than to 'engage' people in the decision-making process. As a result of this, grassroots movements, such as urban guerrilla (Hou 2010) and DIY/DIWO ${ }^{1}$ (Caldwell and Foth 2014, 2017) movements, have encouraged bottom-up community engagement through localised urban interventions. These approaches empower citizens to identify topics and issues that need to be addressed within local communities.

Through our research on situated community engagement, we have found that drawing on the collective knowledge of all actors has a greater opportunity to enable a more collaborative city-making process. This can be achieved by employing a 'middle-out' engagement process (Costa and Ferrão 2010; Fredericks et al. 2016a) that integrates the needs and interests from the decision-makers at the 'top' (e.g. policy-makers) with those of the everyday people from the 'bottom' (e.g. local citizens), which are met somewhere in the 'middle'. Depending on the situation or issues being addressed, this part in the middle (between the top and the bottom) refers to the policy-making process, the community engagement procedure, the social context or the organisational structure. Another critical aspect of 'middle-out' engagement is acknowledging that the city is in a state of perpetual beta, which indicates that the processes of city-making and urban renewal are never complete. These processes are cyclical, occurring in different parts of the city at different times, and need to respond to a range of shifting issues from social to political, environmental to economic.

Community engagement activities range from paper-based interactions to those that are supplemented by digital and physical applications providing new means and interfaces for the formation of 'urban publics' (de Waal 2014). Such novel and complementary approaches to community engagement, aiming to address the shortcomings of traditional processes, are being investigated through the fields of digital placemaking (Fredericks et al. 2016b), urban interaction design (Brynskov et al. 2014), urban HCI (Fischer and Hornecker 2012), urban informatics (Foth et al. 2011), urban computing (Kindberg et al. 2007) and ubiquitous computing (Weiser 1993). This range of novel community engagement approaches and city-making

\footnotetext{
${ }^{1}$ Do It Yourself/Do It With Others.
} 
concepts are helping to improve the use of existing urban infrastructure to provide new opportunities for connecting citizens with their city (Shepard and Simeti 2013; Tomitsch 2014).

To focus on a particular approach that can create novel prospects, pop-up interventions 'hack' public space by appropriating new purposes and temporarily changing the nature and feel of a place. In doing so, they surprise people, stimulate their imagination and create public awareness in citizens (Fredericks et al. 2015). In this chapter, we discuss how situated pop-ups can offer both built environment professionals and local citizens an alternative option for community engagement to ultimately inform and improve the city-making processes. Between 2014 and 2016, we have conducted and investigated a range of situated community engagement activities through the deployment of pop-up interventions in Sydney and Brisbane, Australia.

From our research, we have found that pop-up interventions serve to: (a) raise awareness of the engagement process; (b) encourage community discussion around urban planning, design and architecture topics; (c) involve greater cross sections of the community (e.g. time, poor citizens, younger demographics and culturally and linguistically diverse people); and (d) allow citizens to submit their responses on the spot. Based on our research findings and to facilitate a more collaborative and middleout engagement approach, this chapter presents an urban acupuncture (Lerner 2014) framework for undertaking localised small-scale community engagement activities through pop-up interventions. We discuss two case studies that deployed pop-up interventions in Australia, as different tactics that attempt to give the community a say in the transformation of their city. The framework is intended to encourage citizens to actively identify topics that they would like to see community discussion around. Designers and policy-makers can also apply the framework to guide their city-making strategies. In our approach and through the use of the framework, systemic change in city-making is fostered by accumulating many voices, actors, devices and technologies.

\section{Context}

Local governments are no longer seen as the sole caretakers of cities that have to respond to the needs of their inhabitants. Conventional community engagement processes are still central to the renewal cycle of city improvement; however, it is a difficult task challenged by citizens who are hard to reach and communicate with using archaic engagement mechanisms. We refer to Foth and Brynskov (2016a) who examine civic media and technologies to indicate that "in order to provide meaningful civic engagement, the city must provide appropriate interfaces" (564).

We are interested in exploring what Brynskov et al. (2014) describe as a shift from city management to city-making through urban interaction design. Urban interaction design is the making of urban interfaces to provide a means of citizen engagement (Foth and Brynskov 2016b). These views on the co-creation of cities are in line with the work of de Waal (2014) who examines the city as an interface, and we can 
Table 1 Evolving relationship between cities and citizens (Foth and Brynskov 2017)

\begin{tabular}{l|l|l}
\hline & City government & People \\
\hline City 4.0 & Collaborator & Co-creators \\
\hline City 3.0 & Facilitator & Participants \\
\hline City 2.0 & Service provider & Consumers \\
\hline City 1.0 & Administrator & Residents \\
\hline
\end{tabular}

conclude that both sets of arguments are applicable and compatible with each other. Interfaces in both instances similarly refer to the setting that fosters the adaptation of different systems to one another, such as citizens adapting to the practices of their local community or city (de Waal 2014). Synthesising these thoughts, Foth and Brynskov introduce four stages in the evolution of the relationship between local governments and city residents (Table 1) (Foth and Brynskov 2017). The city operates on multiple scales and can be approached from many angles, but in this chapter we are particularly concerned with the ways in which people leverage technologies for their own purposes to pioneer new community engagement tactics and ultimately bring about a participatory and collaborative approach to city-making.

To support our research and novel approaches to community engagement, we layout the foundations for these evolving relationships between cities and citizens as we strive to go from City 1.0 to reach City 4.0. To better understand the theoretical principals that guide our work, in this chapter we first discuss the concept of perpetual beta and how it applies to the city. We position the perpetual beta concept as a platform that supports the need for situated pop-up interventions as key instigators of change. Second, we discuss the urban acupuncture framework as a guide to inform the development of pop-up urban interventions, such as the two Australian examples discussed. We conclude with a series of questions that explore the potential of cities to move from a state of perpetual beta through a series of accounts and sites to the possibility of producing systemic change.

\subsection{The City as Perpetual Beta}

The twenty-first-century city will never be complete as governments around the world continuously realign strategies to address a myriad of political, social, economic and environmental challenges that engender contemporary society. This unfinished state of cities is not anything new to anyone; however, embracing this unresolved aspect of contemporary cities can be leveraged for the benefit of citizens.

Originally used in the context of software development, the open-source advocate O'Reilly (2015) states, "The open source dictum, 'release early and release often,' in fact has morphed into an even more radical position, 'the perpetual beta,' in which the product is developed in the open, with new features slipstreamed in on a monthly, weekly, or even daily basis". O'Reilly (2015) argues that the 'perpetual beta' 
concept harnesses collective intelligence by acknowledging users as co-developers. Applying this concept to contemporary cities, 'the city as perpetual beta' provides a theoretical lens for city makers and citizens to understand their collective roles in a state of perpetual beta where all users of the city are co-developers of the city.

The concept of perpetual beta has also been applied to other areas outside of software development, such as in business, knowledge management (Levy 2009) and entrepreneurship. In 2010, Pierce (2010) ran a Kickstarter campaign to raise funds in support of the documentary film Life in Perpetual Beta about the influence that technology has on how we consider business and our lives. Perpetual beta in these instances commonly refers to the process of continual improvement, where a finished product would never be good enough. The foundations of the perpetual beta concept connected to technological developments and an open-source approach led us to apply the 'unfinished concept' to that of city-making.

Sassen (2015) refers to this notion of the city as perpetual beta when describing “... an understanding of the city as a combination of incompleteness and complexity: it is this mix that has enabled cities to outlive enterprises, kingdoms, nation-states, and, yes, Cisco Systems" (Sassen 2015, 1). The city, as a concept, is one that is continuously changing, evolving - it shrinks and grows, ebbs and flows, with multiple layers of complexity in both physical forms (buildings, roads, people, trees, etc.) and digital forms (electricity, telecommunications, Internet, etc.). We recognise that the management and administration of a city can be smart, for example, by using technology for controlling traffic patterns, lighting up, sensing weather, managing waste. People can be smart, too, in that they use mobile technology to plan meetings, communicate with anyone, anywhere, record videos, access and create information, seamlessly and simultaneously (Hemment and Townsend 2013). How do these smart citizens who live in smart cities tap into the digital layers of the city's communication flows to inform the creation of the environments in which they live, work and play? If these cities are so smart, how do they use this acquired intelligence of the many to keep getting better and tackling the big social and environmental challenges facing our society and our planet (Foth and Brynskov 2016b)?

\subsection{Urban Acupuncture}

Helping us zoom from the bird's eye view of the city administrator to the pedestrian, that is, local view of the smart citizen, is the notion of urban acupuncture. This concept was originally conceived by the Barcelonan architect and urbanist, Manuel de Sola Morales. The concept aims to use localised small-scale socio-technical interventions to transform the larger urban context (Houghton et al. 2015; Tomitsch et al. 2015). Locations are selected through a comprehensive analysis of social, economic and ecological factors that involves dialogue between designers and communities. Urban acupuncture embraces the city as a living organism (Iaconesi and Persico 2014; Lerner 2014) and identifies areas within cities that require urban renewal. Lerner (2014) describes the essence of urban acupuncture as 
...sometimes, a simple, focused intervention can create new energy, demonstrating the possibilities of a space in a way that motivates others to engage with their community. It can even contribute to the planning process. This gets to the essence of true urban acupuncture-it needs to be precise and quick, that's the secret. (Lerner 2014, 4)

Our research and case studies presented in this chapter are based on this notion of urban acupuncture, each a temporary intervention in an urban space purposefully deployed precisely and quickly to provide people an opportunity to share their ideas or voice their concerns. Building on these principals of urban acupuncture, we focus on how these short-term or 'pop-up' interventions facilitate participation, collaboration and knowledge sharing to ultimately inspire forms or degrees of change.

The urban acupuncture framework we propose draws on the literature from three key areas: (1) existing community engagement within the built environment; (2) digital technologies and their influence on the approach to community engagement; and (3) from top-down to bottom-up to middle-out engagement concepts.

\section{Existing Community Engagement Within the Built Environment}

Community engagement is undertaken by Local Government Authorities (LGAs) around the world to obtain public feedback on the development of infrastructure within the built environment. Through collaboration with communities, businesses and government organisations (Foth and Adkins 2006), community engagement should guide urban planning decisions based on the outcomes of the engagement undertaken (Fredericks et al. 2015). LGAs, as the level of government closest to the people, undertake community engagement, generally as a legislative requirement, to inform communities on the creation of policies and infrastructure developments within the built environment. However, relationships between local communities and LGAs have traditionally played a consultative role, with the level of engagement reduced to informing communities only. As a consequence, the engagement process and the level of community input are controlled by LGAs and are often attributed to political agendas of elected representatives, political party practices and bureaucratic power brokers (Cuthill 2003).

Current methods of community engagement, such as face-to-face workshops, community forums, public hearings and online forms, only reach certain demographics of the population. As a result of this, opinions of community members classified as 'hard to reach' are not reflected in the overall engagement process. Innes and Booher (2004) argue that legally required methods of community engagement in government decision-making rarely achieve genuine engagement outcomes; create dissatisfaction amongst citizens who feel they are not being heard; do not significantly improve the decisions of government agencies; and do not incorporate a broad spectrum of the community. It has been further argued that some traditional engagement practises suffer from a lack of integration between governments and 
the public, and has been shown to have inadequate representation of age groups and demographics (Fredericks et al. 2015; Hosio et al. 2014; Schroeter 2012). Sarkissian et al. (2009) developed the following eight points that identify the underpinnings of successful collaborative community engagement rather than top-down approaches employed by government agencies:

1. People know more than they realise.

2. People cannot participate satisfactorily unless they can understand the language being used.

3. People often fear giving opinions, especially in their local community.

4. People's involvement improves the quality of local government.

5. Synergy is more likely to occur when people collaborate.

6. Specific skills are required.

7. Relevant professionals should be involved from the start.

8. There is community value in sharing participatory experiences.

The eight points place the focus on people not on the policy. The essence of a middle-out approach arises from the needs and will of people to take action for themselves. It is in this spirit that the interventions we discuss in this chapter are directed towards providing a voice for more people.

\subsection{Digital Technologies and Community Engagement}

Within the last decade, information and communication technology (ICT) has evolved from the workplace and integrated into all aspects of daily life (Tomitsch 2014). Moreover, human-computer interaction (HCI) technologies are increasingly being designed for urban environments, such as smartphones and web 2.0 applications. Tomitsch (2014) explains how the ICT industry is in the early stages of exploring the variety of possibilities that new digital technologies offer to make more efficient use of existing infrastructure within the built environment.

Gordon and Manosevitch (2010) introduce the concept of augmented deliberation as a design solution to address challenges where community engagement is complicated by external factors. Augmented deliberation is intended to address a range of social challenges, including language barriers, demographic variations and professional discourse. The intention is to enhance community engagement by incorporating appropriate technologies, for example combining traditional planning practice and public deliberation into a digital environment (Gordon and Manosevitch 2010).

Fredericks and Foth (2013) investigated how social media and web 2.0 applications could be incorporated as additional tools and techniques for community engagement in urban planning. They examined this approach as a way of supplementing traditional methods of community engagement that had a general preference for participants attending an organised consultation event. Additionally, the research explored how community engagement can include a broader cross section of society through the adoption of digital tools. The study concluded that traditional and digital 


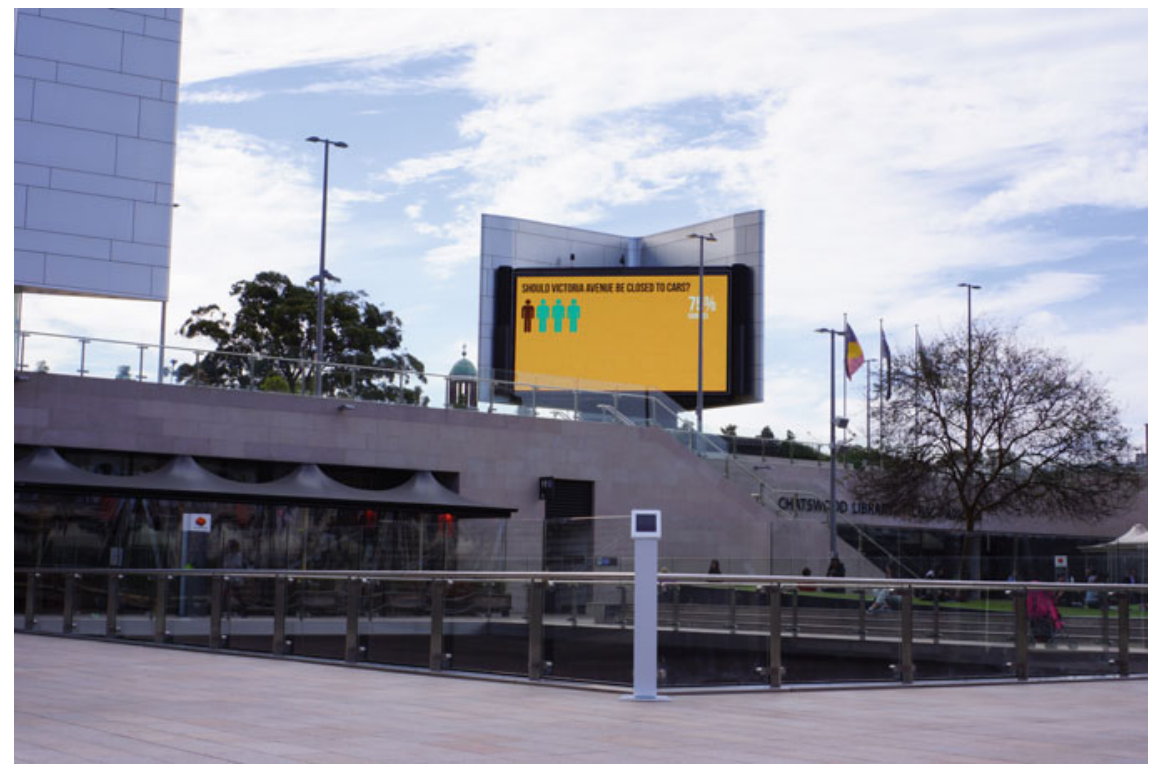

Fig. 1 Screenshot of the urban screen used during the Vote As You Go study

methods of community engagement could be used as a hybrid approach. Furthermore, the research identified that the integration of digital tools presented opportunities to capture a wider audience, attract younger participants and provide communities with the ability to be actively involved in the urban planning process (Fredericks and Foth 2013).

Schroeter and Foth (2009) created Discussions In Space (DIS) as a design experiment to facilitate a locally situated discussion and opinion forum around urban planning topics, issues and questions, which were displayed on a large public screen. Members of the community were able to submit questions directly to the screen using their mobile phone's SMS, Twitter or web capabilities. The messages displayed on the screen in real time provide citizens an additional platform for collective expression and public discourse. Schroeter and Houghton (2011) discuss how community engagement is usually resource and time intensive and how this challenge can be addressed by capturing the attention of digitally savvy community members. They call on LGAs to go with the times by adopting some of the digital channels already well established by corporate entities for the purpose of sales and marketing.

Hespanhol et al. (2015) undertook a research study that deployed two situated Vote As Yоu Go polling interfaces on a public urban screen for community engagement. Engagement questions were posted on the urban screen to obtain community feedback via a polling system (Fig. 1).

The first scenario used a tablet device mounted on a stand that participants could interact with, by simply answering yes or no on the application. The second scenario incorporated a playful full-body interaction application where an outline of 
participants playing with the interface would be visible on the screen. They could then indicate yes or no by using gestures such as moving their hands. The different scenarios allowed the researchers to compare data on participant experiences and the effectiveness of the interface's visibility within an urban space. The study concluded that using these types of interfaces in urban spaces could be an effective strategy for attracting the attention of the general public and converting them into active participants (Hespanhol et al. 2015).

The Smart Citizen Sentiment Dashboard (Behrens et al. 2014) took the form of a media architecture interface, which connected users in public spaces to media façades. Participants were able to activate the media façade of a building by using RFID cards to respond to civic issues pertaining to topics such as safety, transport, housing and public spaces (Behrens et al. 2014). Responses were aggregated and displayed through mood-indicating colours and animations on the screen to represent the overall sentiment of city dwellers. This project is a valuable example of how existing infrastructure, such as a media façade, can be 'hacked' as a type of DIY or DIWO (Caldwell and Foth 2014, 2017). Without dedicated interaction mechanisms (here the RFID interface), city dwellers have no way of interacting with or informing the content displayed on large-scale urban interfaces, such as media façades or urban screens.

Each of these cases exemplifies alternative approaches to community engagement, which rely on different forms of technology to expand the reach and extent of participation from users. Similarly, our projects discussed in this chapter continue to develop a broader understanding for the ways in which different media types (digital, physical and social) can be implemented within the design and deployment of urban interventions. We expand on this research by examining how the different stakeholders' needs and interests are met and responded to and what impact for them and the city at large they may have. The purpose of each example is to increase the levels and depths of community engagement by creatively hacking into public space.

\subsection{City Hacking: From Top-Down to Bottom-Up to Middle-Out Engagement}

Since the early twentieth century cities around the world have established and implemented a variety of urban development paradigms that have shaped the urban fabric within local communities. Government decision-makers have taken a centralised top-down approach in the design and implementation of city-making. For example, Ebenezer Howard conceived the 'Garden Cities of Tomorrow' as a solution to decentralise from congested and unhealthy cities into groupings of 30,000 people along an agricultural green belt (Richert and Lamping 1998). Le Corbusier (1967) created the Radiant City, which has influenced the design of large building blocks through 'brutalism architecture' (Shonfield 2000). This was a top-down and highly controversial solution to address public housing needs across cities in Europe, America and 
Australia. Present-day paradigms such as transit-oriented developments aim to foster economic and residential development around public transport routes and masterplanned communities that incorporate civic services, residential housing and public amenities. Although these top-down initiatives have varying degrees of success in creating urban environments, many citizens across the world continue to feel disempowered or unheard when it comes to urban development. Traditional approaches still employed by LGAs are outdated, have the ability to fragment communities and exclude certain demographics of society (Fredericks et al. 2015; Sarkissian et al. 2009; Schroeter 2012).

As a result, many people are taking matters into their own hands with growing evidence of bottom-up approaches to city-making. Community members have taken it upon themselves to test the needs, wants and aspirations of civic spaces in modern society. This contemporary approach has led to bottom-up localised urban interventions in the form of pop-ups - referred to as pop-up urbanism (Fredericks et al. 2015), tactical urbanism (Lydon et al. 2014), guerrilla urbanism (Caldwell et al. 2015; Hou 2010), DIY/DIWO urbanism (Caldwell and Foth 2014; Douglas 2014; Iveson 2013) and urban acupuncture (Houghton et al. 2015; Iaconesi and Persico 2014; Lerner 2014; Tomitsch et al. 2015). Pop-up interventions 'hack' public space by appropriating new purposes and temporarily changing the nature and feel of a place. These approaches can be used as temporary installations that are either set up for a few hours or for an extended period of time.

The Better Block project ('Better Block' 2016), which is being implemented in many cities throughout the USA, is an example of rapid urban revitalisation or otherwise known as guerrilla urbanism (Caldwell et al. 2015; Hou 2010). Being a community-driven initiative, the Better Block project aims to revive underutilised city blocks by retrofitting these spaces to promote pedestrian and cyclist activity through temporary interventions, such as pop-up shops, positioning of trees and painting bike lanes onto the road. The project thus utilises existing community resources to create multi-modal transportation that takes the focus away from private vehicle-dominated roads. These temporary interventions enable communities to experience the potential of underutilised spaces and how they can be repurposed as usable civic space.

Attempts to employ more collaborative engagement approaches have seen partnerships established between LGAs and local communities to create a middle-out approach for community engagement. The concept of middle-out was coined by Kinchla and Wolfe (1979) as a collaborative process that draws on the knowledge from higher (top-down) and lower (bottom-up) information channels that come together and meet in the middle. An example of this is the PopUp MANGo temporary street festival where local citizens could interact with proposed urban design and roadway changes through a collaborative design process. ${ }^{2}$ The pop-up intervention included temporary traffic calming devices, a parklet with plants and seating, live entertainment, food trucks and activities for children. The event was organised as a partnership between the LGA, an urban planning and design consultancy, and

\footnotetext{
${ }^{2}$ PopUpMANGo https://www.smgov.net/uploadedFiles/Departments/PCD/Plans/Streetscapes/ Michigan-Ave-Greenway/PopUpMANGo_Summary_Sheet.pdf.
} 
local community groups. This approach provided all stakeholders with an opportunity to evaluate the proposal within the space and be involved in the planning process through a practical hands-on approach. As a result of this community engagement event, a concept plan was created based on the feedback of all stakeholders.

Pop-up town halls are another example of informal and collaborative community engagement that provides opportunities to involve a variety of top-down and bottomup stakeholders. These types of pop-up interventions are located in public space that is easily accessible to community members in comparison with traditional events held within specific time frames and locations (e.g. charrettes, town hall events, public workshops). They can utilise unused civic spaces and empty shop fronts; however, for maximum impact they should be located in an area of high pedestrian activity and be held in parallel with other public events, such as festivals, exhibitions and conferences.

Pop-up interventions have the potential to hack into the collective knowledge of all stakeholders within local communities. This provides opportunities to encourage a more rich and open civic discussion, enable collaboration between a variety of top-down and bottom-up stakeholders and inspire the exchange of ideas (Fredericks et al. 2016a; Lydon et al. 2014). We will further expand on these examples through our filed studies below by demonstrating a middle-out (Costa and Ferrão 2010; Fredericks et al. 2016a; Janda and Parag 2013) engagement approach that aims to integrate the needs and interests from LGAs (top-down) with those of the everyday people (bottom-up).

\section{Urban Acupuncture Framework}

Linking our research to the previous examples from HCI, media architecture and urban planning, we discuss two pop-up interventions in this chapter that were concerned with community engagement in two different Australian cities. Reflecting on the design process leading to the interventions and the result from their deployment evaluations, we have developed an urban acupuncture framework (Fig. 2), which asus in highlighting the decision-making process for implementing pop-up interventions in-the-wild. The concept of conducting research in-the-wild refers to the testing of prototypes in public space to see how they are adapted and used in everyday life (Chamberlain et al. 2012). Evaluation in-the-wild can include the recording and observation of how people interact with, adapt and use the prototype providing a different approach than testing in controlled laboratory environments (Chamberlain et al. 2012). Many researchers in the HCI field have incorporated inthe-wild approaches to their research and design development, whereas in urban studies research is constantly tested in the built environment and has always been 
Urban Acupuncture Through “Pop-Up” Interventions

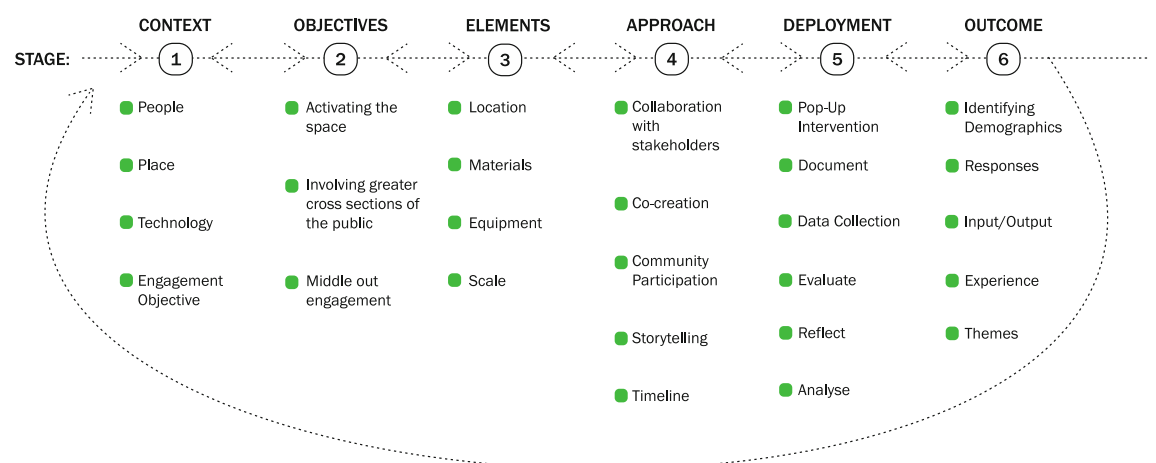

Fig. 2 Urban acupuncture framework using pop-up interventions. Source Authors

in-the-wild. ${ }^{3}$ Recent research pertaining to media architecture and urban interfaces has also relied on in-the-wild research (Fatah gen Schieck et al. 2014; Hoggenmüller and Wiethoff 2014).

Our urban acupuncture framework applies a participatory action research methodology (Foth and Brynskov 2016a; Hearn et al. 2009) with the intention to include local stakeholders in the different planning stages of the interventions. The urban acupuncture framework draws together the previously reviewed concepts of, the city as perpetual beta and middle-out community engagement. The framework is intended to be used as part of an iterative process within an engagement strategy where the pop-up intervention would be deployed in different locations across the city responding to different issues. Due to their agile nature, the pop-ups can respond in each step or iteration to the needs of the context and people involved in the deployments. The framework does not provide an answer or a mechanism towards the completion of a city; it is a process that assists citizens to in-act their role as co-developers in a perpetual beta city. The urban acupuncture framework can be used by individuals, within groups or across groups of people as a vehicle for communication and idea generation across the different stakeholders from the top, the bottom and the middle.

The framework consists of six stages: context, objectives, elements, approach, deployment and outcome. Each stage is made up of different concepts that require consideration when creating and deploying a pop-up intervention.

1. Context - The first stage is to examine and understand the local context including the people who create the places within it. The use and type of technology that will be utilised and the needs to be considered in line with the engagement objectives.

\footnotetext{
${ }^{3} \mathrm{We}$ acknowledge that there is a trend to the opposite where urban science is pushing for more 'modelling' using big data analytics, so the focus of that part of the research community is going back into the 'laboratory'.

${ }^{2}$ For example, see these websites: civicmediaproject.org, beautifultrouble.org, citystudiovancouver.com.
} 
2. Objectives-The second stage focuses on the objectives of the intervention including how to activate the public space by involving a greater cross section of the public through a variety of tools or approaches within the pop-up, informing local communities about the engagement activity to promote collaboration and interaction with the intervention. Stage one and two often inform each other and do not necessarily occur in a linear manner, and they can be developed in parallel.

3. Elements - The third stage takes into consideration certain design elements of the pop-up, such as the location, timing and duration, in addition to the materials and equipment required to construct it. The size and scale of the pop-up are also important factors to consider when addressing the context of the site.

4. Approach - The fourth stage addresses the approach undertaken for implementing the pop-up intervention, including collaboration with top-down (LGAs, private enterprise) and bottom-up (local citizens, community groups) stakeholders to co-create the engagement process.

5. Deployment - The fifth stage considers the actual deployment of pop-up interventions in public spaces. This includes the mechanisms to document and collected data and how it can be evaluated and analysed.

6. Outcome-The sixth and final stage identifies the results of installing the popup intervention, including the identification of engagement themes and a deeper understanding of local demographics needs, wants and aspirations. The responses collected through the intervention in both their input and output formats can be analysed to discover recurring themes arising from the contributions of the participants.

The following field studies are the basis on which the framework was developed. The case studies as discussed in the following sections demonstrate how this framework can be implemented using situated pop-up interventions in two different Australian cities: Sydney and Brisbane. Both studies formed part of two existing community engagement programmes with official stakeholders deciding the engagement objectives prior to the pop-up deployment. However, we employed a transdisciplinary approach in the design and development of the engagement activities, which included informal meetings with local stakeholders and co-design workshops.

The two case studies were developed and deployed in parallel and independent of each other; however, the design concept and engagement approaches informed one another. Through our collaborative approach between the Design Lab (University of Sydney) and the Urban Informatics Research Lab (Queensland University of Technology), we have come together to review our learning from the research within the different contexts of Sydney and Brisbane. We acknowledge that addressing broad theoretical concepts such as the city as perpetual beta, urban acupuncture and middleout engagement approaches requires input from multiple perspectives and contexts. Therefore, this chapter and the framework we have collaboratively developed are a first step towards addressing these much larger questions regarding participatory methods for city hacking. 


\subsection{Study I: Digital Pop-Up}

\section{Context}

Digital Pop-Up was implemented in collaboration with an LGA in Sydney, Australia. It is a result of a multidisciplinary research team from the Design Lab, University of Sydney, involving an urban planner, interaction designer, visual designer and creative technologist. The findings of this study were published by Fredericks et al. (2015). We deployed three variations of our pop-up intervention over three separate days within a busy public square consisting of: (1) a stand-alone tablet device on a stand with a customised voting web interface juxtaposed with an existing urban screen, during a regular workday; (2) an unstaffed pop-up during a cultural festival using a tablet device, an adapted web interface that allowed text responses, the urban screen, market umbrella, synthetic turf and barstools; and (3) a staffed pop-up during a regular workday utilising the same tablet device with web interface, the urban screen, gazebo structure, synthetic grass, ottoman seating, plants and 'call-to-action' signage, which was displayed on the urban screen and on physical posters at the pop-up.

\section{Objectives}

The objective of this study was to obtain community feedback on how to promote healthy lifestyles and improve recreational needs within the community. Specifically, our intention was to engage with a variety of demographics, including local office workers, business owners and people who are culturally and linguistically diverse. In addition to that, we wanted to deploy a pop-up intervention that included the engagement objectives of the LGA, but was able to openly capture the needs, wants and aspirations of local citizens without any interference from other actors.

\section{Elements}

The civic space in which this study was conducted is used by local residents, office workers and as a pedestrian thoroughfare. The location is surrounded by an entertainment quarter, restaurants, a public library and is within close proximity to a large shopping precinct and public transport interchange. The civic space also features an existing urban screen used for delivering a variety of entertainment content and a grassed open space used as a meeting point and for social gatherings. The first iteration of this study was deployed for a total of two hours and incorporated a standalone tablet device on a stand that was used in conjunction with the existing urban screen. The tablet device was situated diametrically opposite the urban screen, which was located on the intersection of two walkways exposed to continuous pedestrian movement. The second iteration was deployed for a total of two hours within the same civic space, incorporating the tablet device on a stand, and market umbrella and seating. The third iteration was also deployed for a total of two hours; however, a gazebo structure was used and call-to-action signage was introduced on the urban screen and surrounding the pop-up to draw attention to the engagement activities. 


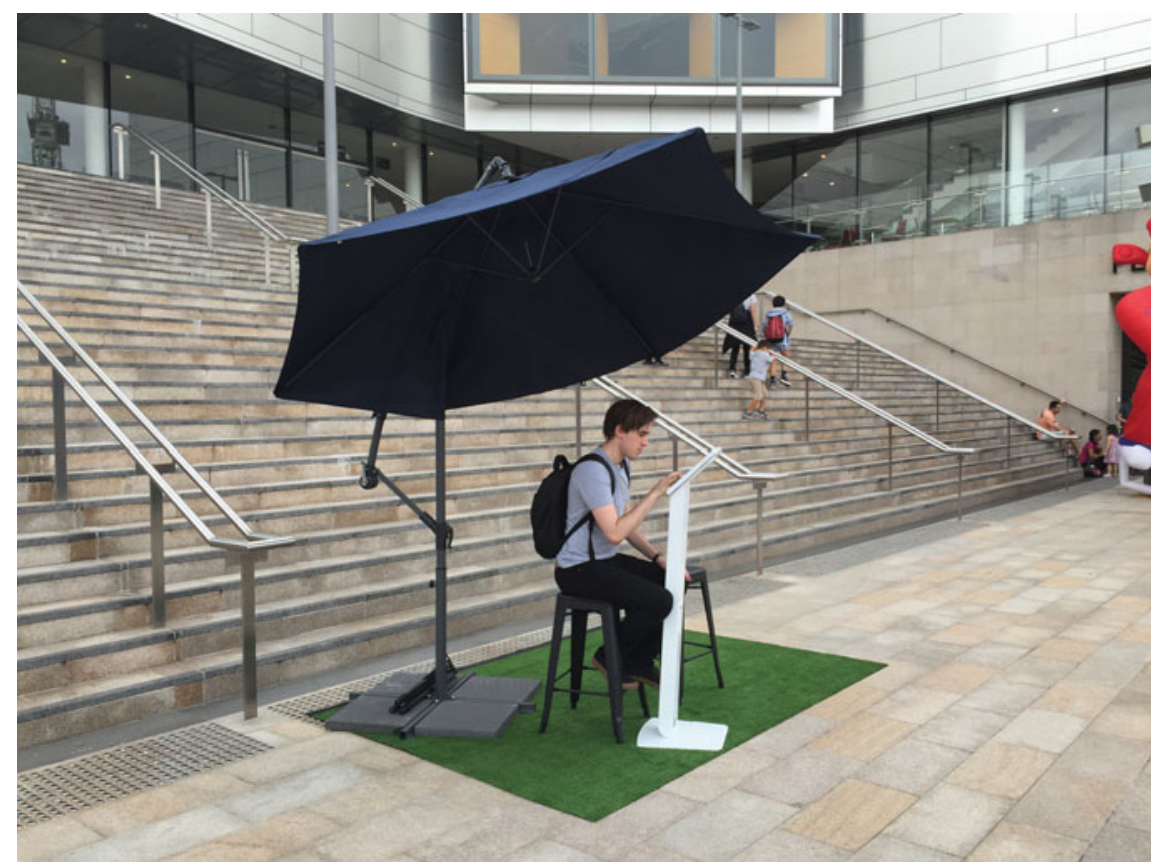

Fig. 3 Study 1 pop-up design

\section{Approaches}

We held informal meetings with a representative from the LGA (top-down decisionmaker) to discuss the engagement objectives, including the contextual information, engagement questions and types of demographics they wanted to capture. In addition to this, we employed a transdisciplinary research team for the design and development of our pop-up interventions. Over a 3-month period, we evaluated and tested our designs, which we continuously refined based on observations and participant feedback during the deployments. For the purpose of this study, the bottom-up component incorporated the community interactions during the three deployments and the feedback received from participants regarding the pop-up set-up and functionality.

\section{Deployment}

Our overall goals for this study were (1) to draw attention to the engagement activity; (2) to create discussion around healthy built environment; and (3) to provide a space for participants to interact within the civic space. Each of the studies utilised the existing urban screen, which was used as the output channel to display the community engagement questions and participant responses in conjunction with a tablet device with a customised web interface that served as the input channel for participant responses (Figs. 3 and 4). 


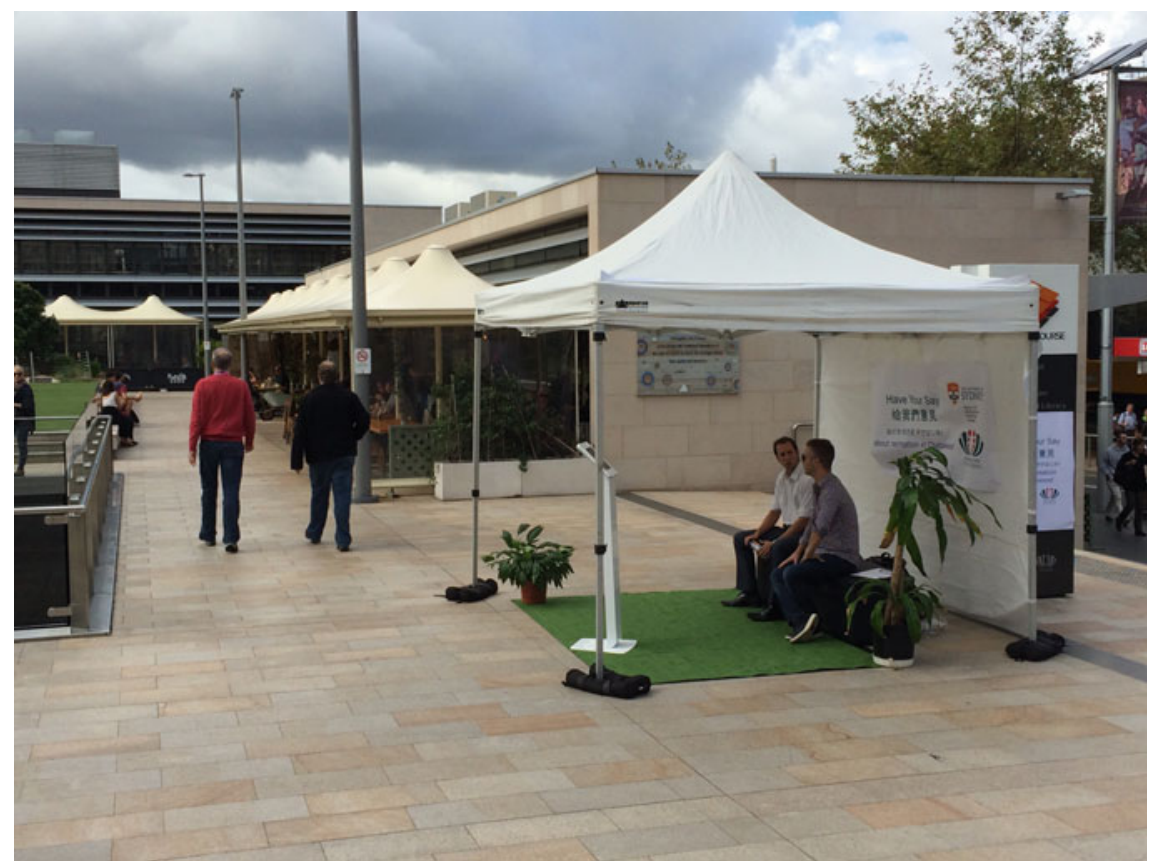

Fig. 4 Study 2 pop-up design

\section{Outcome}

Data collected from the three iterations produced valid responses in regard to LGA services and healthy lifestyles with a total of 27 responses received. In addition to this, we undertook 13 semi-structured interviews with willing participants. All participants expressed positive feedback regarding Digital Pop-Up, reflecting that this approach to community engagement works well in contemporary society and is not something that is not normally located in a civic space. Representatives from the LGA highlighted that Digital Pop-Up is an effective approach to complement existing community engagement approaches and has a greater potential to attract a younger demographic. Our case study showed how this approach deployed within a civic space provides citizens the option to participate on the spot, with little effort in comparison with attending an organised engagement event during a specific time frame. Our study further demonstrated how existing digital technologies, such as tablets and urban screens, can be easily appropriated to engage citizens in a pop-up environment within a civic space. 


\subsection{Study II: InstaBooth}

\section{Context}

The InstaBooth is a telephone booth inspired portable flat-packed structure that has been designed and fabricated to enable an alternative approach to community engagement (Johnstone et al. 2015; Caldwell et al. 2016). The InstaBooth incorporates a combination of interactive modules with different types of physical and digital media to ask questions of its users and gather feedback. It is the result of a transdisciplinary research project led by researchers from the Urban Informatics Research Lab, Queensland University of Technology, that consists of team members from the disciplines of architecture, urban planning, interior design, interaction and visual design, computer science, business and urban informatics. In collaboration with the U.R $\{B N E\}$ Collective (urbne.com), an independent group of urban planners, architects, designers and artists, the InstaBooth (Figs. 5 and 6) was deployed in April 2015 during the U.R $\{$ BNE $\}$ Festival. The festival is an annual event held within the Brisbane central business district with the purpose of bringing together a range of artistic, design and social interventions to inspire people to question the future of the city of Brisbane.

\section{Objectives}

The nature of the deployment and the types of questions asked through the InstaBooth during the U.R. $\{$ BNE $\}$ Festival were discussed and elaborated based on collaboration with the festival-organising committee and the InstaBooth team. The questions and interaction modules were designed to gather insight into the community on their needs for better infrastructure to promote healthy and active lifestyles including better food

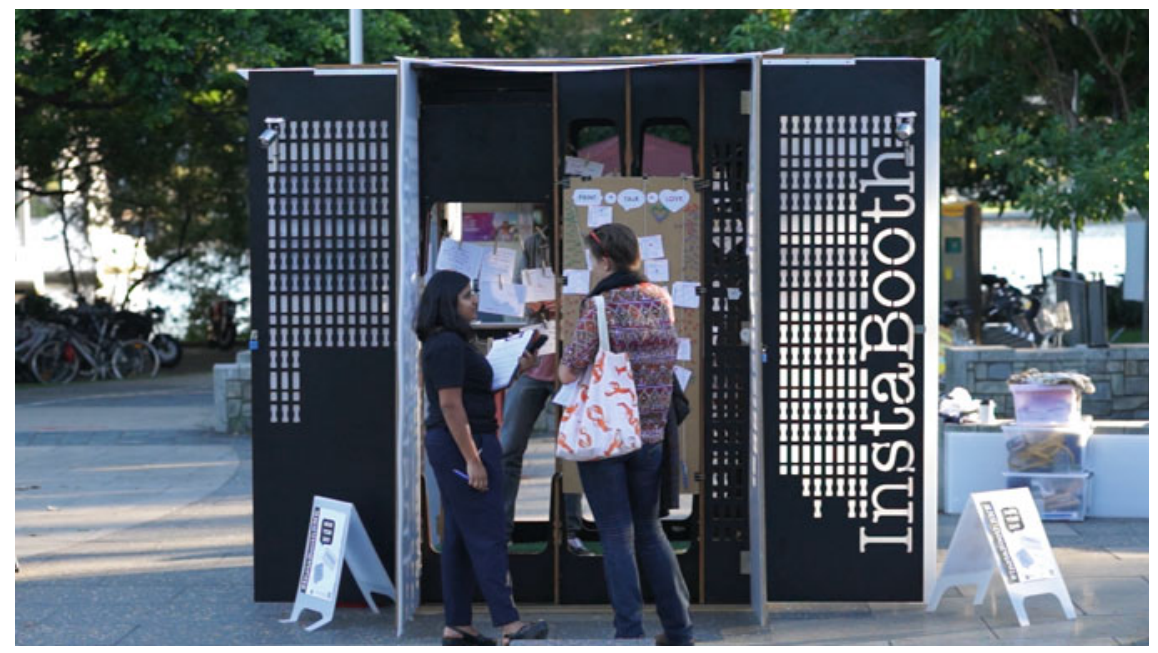

Fig. 5 InstaBooth design 


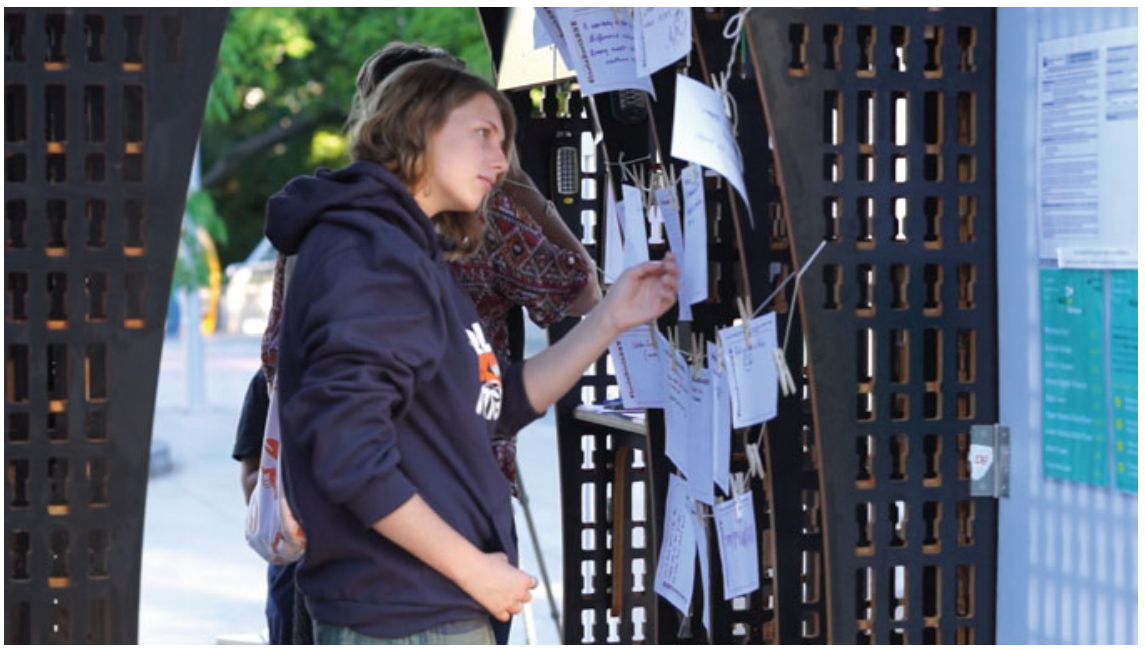

Fig. 6 InstaBooth activities

options. This approach was in line with the overarching theme of the festival which focused on creating a vision of a better future for Brisbane. The InstaBooth was viewed by the festival committee as an opportunity to trial an alternative approach to traditional community engagement. The combination of digital and physical media and design of the questions as part of the engagement strategy was purposefully designed to attract the engagement of more people from diverse backgrounds, cultural and age groups.

\section{Elements}

During the U.R $\{$ BNE $\}$ Festival, the InstaBooth was installed in two distinct locations in the Brisbane central business district over the course of 5 days. In the first location, the InstaBooth was set up for a Friday evening at the location of the main event of the festival, a park in inner-city Brisbane. During this event, the local city council conducted a formal community consultation on development ideas for that precinct. In addition, there were food trucks, live music, art installations and projection art as part of the festival. The second location was on the edge of the Queensland University of Technology (QUT) campus and next to a busy pedestrian and cycle bridge linking the Brisbane central business district with the cultural precinct across the river. The InstaBooth was set up for 4 days and evenings. There were no other events as part of the festival occurring at this location. During this deployment at the two locations, the compilation of interaction modules and the questions asked through them remained the same. The InstaBooth had a range of interactive modules including paper-based questions, iPads with photograph sharing and voting options, an overhead projector and Discussions in Space (Schroeter and Foth 2009) a screen-based consultation tool that promotes a question, and responses are collected through Twitter or SMS. The data collected was concerned with three aspects of the InstaBooth project; (1) the 
experience of the user with the InstaBooth; (2) the comments and drawings created by the users in response to set questions; and (3) observations.

\section{Approaches}

The composition of the interaction modules included a range of paper and tangible media to allow for a greater range of participation and interaction to occur regardless of a user's ability to use specific technology or ability to write. The bespoke design of the InstaBooth including the open and anonymous nature of the interaction modules stimulated playful yet authentic forms of dialogue to occur within the commentary and drawings collected through the InstaBooth during U.R. $\{B N E\}$. The level of engagement within the InstaBooth was controlled by the participants which helped to foster a sense of empowerment. This process allowed for users to co-create the media content within the InstaBooth (Caldwell and Foth 2017).

\section{Deployment}

To evaluate the experience that users had with the InstaBooth, 27 participant interviews were conducted. The responses collected from the people through the interaction modules increased over the days of deployment perhaps indicating a level of growing comfort or increased curiosity of the InstaBooth. The overall sentiment was generally positive. In total, 138 notes and drawings were collected through the paper-based interactions, and 6 text and Twitter messages were recorded through the digital module.

\section{Outcome}

A thematic analysis (Braun and Clarke 2006) was conducted on the comments (paper and digital) and drawings that were captured through the InstaBooth. The findings indicated that participants tended to seek more playful physical infrastructure, greater variety of healthy food options and diversity of cultural and social events to promote better health within the city of Brisbane. During its deployment at the festival and through the different interaction modules and media types, the InstaBooth created a temporary place for voicing concerns, sharing ideas and learning from others that was open and accessible to anyone. The observations and experience from this initial deployment of the InstaBooth informed design changes to some of the interactive modules, mainly to improve their ease of use for future deployments of the InstaBooth. Following the U.R. $\{$ BNE $\}$ Festival, the InstaBooth to date has been involved in 15 communities and public events throughout Brisbane and southeast Queensland since 2015. The InstaBooth has shown how an urban intervention such as a 'pop-up' structure can 'hack' into parts of the city to transform them from public spaces to places that generate discussion, learning and different forms or levels of community engagement to occur. 


\subsection{Contribution to City Hacking}

Applying the notion of the city as perpetual beta where all users are co-developers is fundamental to situated pop-up interventions. The field studies were designed based on participatory and co-design methodologies as a form of DIY/DIWO media architecture (Caldwell and Foth 2014, 2017). This approach is characterised by its temporary, pop-up nature as urban acupuncture by capturing the pulse of its users. Its combination of playful materials and media not only stimulates the interaction and engagement of its users but also inspires them to think, reflect, share and act. Situated pop-up interventions can perform on multiple levels to reach across the people from the bottom, to the top, acting as a middle-out approach to community engagement. Our two field studies were partnered with LGAs, government agencies and private entities (people at the top of the decision-making process) who were seeking a communication channel with everyday people (at the bottom). Developing the engagement strategy with the stakeholders is a crucial aspect of its success as the media through which the questions are asked have to be designed and tailored to suit the context and place of intervention. This collaborative approach involves the stakeholders in part of the design process, thereby extending the value and appreciation they have towards the engagement strategy. Similarly, the creative process through which users respond to different interactive modules and questions empowers them to be a part of the engagement strategy. It is within this strategy and the space provided by these situated pop-ups that the people meet in the middle.

By providing a small temporary space for questioning, reflecting, learning, expression and fun, within the larger city domain, these interventions not only hack into the city infrastructure but hack into the city-making process. Embracing the middle-out approach where people at the bottom and the top feel empowered, the outcomes of Digital Pop-Up and InstaBooth as a means to city hacking is strategic in deepening its impact towards a more open and inclusive form of city-making.

\section{Implementing Systemic Change}

\footnotetext{
Everyone knows that planning is a process. Yet no matter how good it may be, a plan by itself cannot bring about immediate transformation. Almost always, it is a spark that sets off a current that begins to spread. This is what I call good acupuncture - true urban acupuncture. (Lerner 2014, 3)
}

In this contribution, we have proposed an urban acupuncture framework to assist in creating urban interventions that are based on the community engagement objectives, location of the activity and duration for pop-up interventions. To exemplify how the framework can be implemented, we presented two middle-out (Costa and Ferrão 2010; Fredericks et al. 2016a) city hacking activities through pop-up interventions that were undertaken at two different locations in Australia. We argue that city hacking through pop-up interventions can contribute to systemic change in both 


\section{Urban Acupuncture Through “Pop-Up” Interventions}

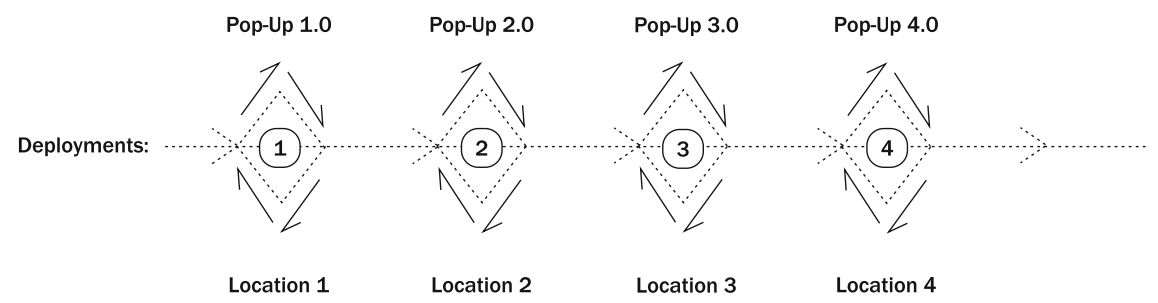

Fig. 7 Pop-up deployments in different locations to foster systemic change

local communities and across entire metropolitan areas, fostered by the accumulation of many voices, actors, devices and technologies. Figure 7 conceptualises a series of pop-up interventions that individually address the locations in which they are situated; however, it is the evolution and series of pop-ups building on each other that will assist in creating systemic change.

An example of systemic change created through city hacking is PARK(ing) Day ('PARK(ing) Day' 2016). This DIY urbanism concept or 'hacktivism' has evolved from an unauthorised reclaim of public space into 'parklets'. The parklet concept is an example of systemic change through the support gained by elected representatives, government agencies and communities throughout the USA, Europe and Australia and has become an acceptable reclaim of public space beyond a 'one day a year' intervention (Mustafa et al. 2014). We point out similarities to the concept of 'perpetual beta', in the context of the built environment, where a city is continually changing, evolving and growing. The pop-up approach is particularly promising for addressing increased pressures on infrastructure within the built environment, such as population growth, housing densities and public transport. Perhaps, our cities do not need more infrastructure, and instead we should use what we already have in a better way? Similarly, the notion of 'infrastructure' could extend to the entire city (Ratti 2015) and also consider the city's 'infostructure' (Tomitsch and Haeusler 2015) as a way of making better use of existing resources.

Although parallels can be drawn between urban acupuncture through localised small-scale interventions, such as the Digital Pop-up and InstaBooth case studies discussed in this chapter, results informing city-making, however, depend on the community engagement methods used. For example, employing a participatory action research methodology (Foth and Brynskov 2016a; Hearn et al. 2009) by involving LGAs, community groups, organisations and relevant stakeholders from the outset of the engagement activity is promoted in order to create a middle-out approach. It should be highlighted that LGAs undertake engagement with the intention of obtaining community feedback as a legislative requirement (Innes and Booher 2004); however, the decision-making process and power still lie with the LGA and not the community. Traditionally, urban acupuncture has been used to create a dialogue 
between designers and communities around architecture projects located in areas that had been identified as needing repair. We propose to extend this definition to include city hacking through pop-up interventions for community engagement, to obtain public feedback on infrastructure within the built environment. Through this attitude, we encourage LGAs to explore the idea of opening their cities to hacking in order to create an open-source city. This can be achieved by lowering regulations and restrictions for the deployment of pop-up interventions, hosting hack-a-thons, providing hackable spaces and sharing data and resources to encourage citizens to question and provide solutions to city-making. Additionally, this approach can be used for both locally based (e.g. urban renewal in a local community) and citywide projects (e.g. improvements to city pedestrian and cycle paths).

We have shown that implementing the urban acupuncture framework has encouraged a middle-out approach to community engagement by drawing on the collective knowledge of top-down and bottom-up stakeholders. This concept further explores how the final outcomes of each local intervention can contribute to systemic change past the individual locale and - taken together-across different urban environments. We propose the urban acupuncture framework as a dynamic, continuously evolving tool, to be adopted, further expanded and developed by practitioners of community engagement, urban planners, designers, architects, academics and community members who contribute to the engagement process.

\section{References}

Behrens, Moritz, Nina Valkanova, Ava Fatah gen Schieck, and D.P. Brumby. 2014. Smart citizen sentiment dashboard: A case study into media architectural interfaces. In Proceedings of the 3rd ACM international symposium on pervasive displays, 19-24. New York: ACM.

Better Block. 2016. http://betterblock.org. Accessed 23 July 2018.

Braun, Virginia, and Victoria Clarke. 2006. Using thematic analysis in psychology. Qualitative Research in Psychology 3 (2): 77-101.

Brynskov, Martin, Juan Carlos Carvajal Bermudez, Manu Fernandez, Henrik Korsgaard, Ingrid Mulder, Katarzyna Piskorek, Lea Rekow, and Martijn de Waal. 2014. Urban interaction design: Towards citymaking. Amsterdam: Book Sprints.

Caldwell, Glenda Amayo, and Marcus Foth. 2014. DIY media architecture: Open and participatory approaches to community engagement. In Proceedings of the 2 nd media architecture Biennale, 1-10. Aarhus: ACM.

Caldwell, Glenda Amayo, Lindy Osborne, Inger Mewburn, and Philip Crowther. 2015. Guerrillas in the [urban] midst: Developing and using creative research methods-guerrilla research tactics. Journal of Urban Technology 22 (3): 21-26.

Caldwell, Glenda Amayo, Mirko Guaralda, Jared Donovan, and Markus Rittenbruch. 2016. The InstaBooth: Making common ground for media architectural design. In Proceedings of the 2016 media architecture Biennale. Sydney: ACM.

Caldwell, Glenda Amayo, and Marcus Foth. 2017. DIY/DIWO media architecture: The InstaBooth. In Using information and media as construction material, ed. Alexander Wiethoff and Heinrich Hussmann, 61-80. Berlin: DeGruyter.

Chamberlain, Alan, Tom Rodden, Matt Jones, and Yvonne Rogers. 2012. Research in the wild: Understanding "in the wild" approaches to design and development. In Proceedings of the 2012 ACM conference on designing interactive systems, 795-796. Newcastle Upon Tyne: ACM. 
Corbusier, Le. 1967. The radiant city: Elements of a doctrine of urbanism to be used as the basis of our machine-age civilization. New York: Orion Press.

Costa, Inês Santos, and Paulo Ferrão. 2010. A case study of industrial symbiosis development using a middle-out approach. Journal of Cleaner Production 18 (10-11): 984-992.

Cuthill, Michael. 2003. Urban policy and research 21 (4): 373-391.

de Waal, Martijn. 2014. The city as interface. How new media are changing the city. Rotterdam: Nai010 Publishers.

Douglas, Gordon C.C. 2014. Do-it-yourself urban design: The social practice of informal "improvement" through unauthorized alteration. City and Community 13 (1): 5-25.

Fatah gen Schieck, Ava, Holger Schnadelbach, Wallis Motta, Moritz Behrens, Steve North, Lei Ye, and Efstathia Kostopoulou. 2014. Screens in the wild: Exploring the potential of networked urban screens for communities and culture. In Proceedings of the international symposium on pervasive displays, 166 . Copenhagen: ACM.

Fischer, Patrick Tobias, and Eva Hornecker. 2012. Urban HCI: Spatial aspects in the design of shared encounters for media facades. In Proceedings of human factors in computing systems, 307-316. New York: ACM.

Foth, Marcus, and Barbara Adkins. 2006. A research design to build effective partnerships between city planners, developers, government and urban neighbourhood communities. The Journal of Community Informatics 2 (2).

Foth, Marcus, and Martin Brynskov. 2016a. Participatory action research for civic engagement. In Civic media: Technology, design, practice, ed. Eric Gordon and Paul Mihailidis, 563-580. Cambridge: MIT Press.

Foth, Marcus, and Martin Brynskov. 2016b. Participation in Urban Interaction Design for Civic Engagement. In What urban media art can do-Why when where and how? ed. Susa Pop, Tanya Toft, Nerea Calvillo, and Mark Wright. Stuttgart: Av edition.

Foth, Marcus, and Martin Brynskov. 2017. Urban informatics and interaction design for cities. San Rafael: Morgan and Claypool Publishers.

Foth, Marcus, Jaz Hee-Jeong Choi, and Christine Satchell. 2011. Urban informatics. In Proceedings of the ACM 2011 conference on computer supported cooperative work. New York: ACM.

Fredericks, Joel, and Marcus Foth. 2013. Augmenting public participation: Enhancing planning outcomes through the use of social media and web 2.0. Australian Planner 50 (3): 244-256.

Fredericks, Joel, Martin Tomitsch, Luke Hespanhol, and Ian McArthur. 2015. Digital pop-up: Investigating bespoke community engagement in public spaces. In Proceedings of the annual meeting of the Australian special interest group for computer human interaction, 634-642. Melbourne: ACM.

Fredericks, Joel, Glenda Amayo Caldwell, and Martin Tomitsch. 2016a. Middle-out design: Collaborative community engagement in urban HCI. In Proceedings of the annual conference of the Australian computer-human interaction special interest group, 200-204. New York: ACM.

Fredericks, Joel, Luke Hespanhol, and Martin Tomitsch. 2016b. Not just pretty lights: Using digital technologies to inform citymaking. In Proceedings of the 2016 media architecture Biennale. Sydney: ACM.

Gordon, Eric, and Edith Manosevitch. 2010. Augmented deliberation: Merging physical and virtual interaction to engage. New Media and Society 13 (1): 75-95.

Hearn, Greg, Marcus Foth, and June Lennie. 2009. Action research and new media: Concepts, methods and cases. Cresskill: Hampton Press.

Hemment, Drew, and Anthony Townsend, eds. 2013. Smart citizens. Future Everything Publications.

Hespanhol, Luke, Martin Tomitsch, Ian McArthur, Joel Fredericks, Ronald Schroeter, and Martin Foth. 2015. Vote as you go: Blending interfaces for community engagement into the urban space. In Proceedings of the 7th international conference on communities and technologies, 29-37. Ireland: ACM.

Hoggenmüller, Marius, and Alexander Wiethoff. 2014. LightSet: Enabling urban prototyping of interactive media façades. In Proceedings of 2014 ACM conference on designing interactive systems, 925-934. New York: ACM Press. 
Hosio, Simon, Jorge Goncalves, Vassilis Kostakos, and Juka Riekki. 2014. Exploring civic engagement on public displays. In User-centric technology design for nonprofit and civic engagements, ed. Saqib Saeed, 91-111. Cham: Springer International Publishing.

Hou, Jeffrey. 2010. Insurgent public space: Guerrilla urbanism and the remaking of contemporary cities. London; New York: Routledge.

Houghton, Kirallie, Jaz Hee-jeong Choi, and Arthur Lugmayr. 2015a. Urban acupuncture. Journal of Urban Technology 22 (3): 1-3.

Houghton, Kirallie, Marcus Foth, and E. Miller. 2015b. Urban acupuncture: Hybrid social and technological practices for hyperlocal placemaking. Journal of Urban Technology 22 (3): 3-19.

Iaconesi, Salvatore, and Oriana Persico. 2014. Urban acupuncture in the era on ubiquitous media. The Journal of Community Informatics 10 (3).

Innes, Judith E., and David E. Booher. 2004. Reframing public participation: Strategies for the 21st century. Planning Theory and Practice 5 (4): 419-436.

Iveson, Kurt. 2013. Cities within the city: Do-it-yourself urbanism and the right to the city: do-ityourself urbanism and the right to the city. International Journal of Urban and Regional Research 37 (3): 941-956.

Janda, Kathryn B., and Yael Parag. 2013. A middle-out approach for improving energy performance in buildings. Building Research and Information 41 (1): 39-50.

Johnstone, Sarah, Glenda Amayo Caldwell, and Markus Rittenbruch. 2015. Defining the InstaBooth: Facilitating debate and content creation from situated users. In Proceedings MEDIACITY 5, international conference, workshops and urban interventions. Plymouth: School of Architecture, Design and Environment and Institute of Digital Art and Tehnology.

Kinchla, R.A., and Jeremy Wolfe. 1979. The order of visual processing: "Top-down," "bottom-up," or "middle-out." Perception and Psychophysics 25 (3): 225-231.

Kindberg, Tim, Matthew Chalmers, and Eric Paulos. 2007. Urban computing. IEEE Pervasive Computing 6 (3): 18-20.

Lerner, Jamie. 2014. Urban acupuncture. Washington, D.C.: Island Press.

Levy, Moria. 2009. WEB 2.0 implications on knowledge management. Journal of Knowledge Management 1 (13): 120-134.

Lydon, Mike, Lucinda Hartley, Alex Mengel, Katie Wallace, M. Budahazy, Nicolas Monisse, Melissa Yee, and S. Kearney. 2014. Tactical urbanism 4. Street Plans Collaborative.

Mustafa, Zaki, Valerie Watson, and Steven B. Colman. 2014. Partnering for parklets. ITE Journal 84 (9): 36-40.

O'Reilly, Tim. 2015. What is web 2.0. O'Reilly. http://www.oreilly.com/pub/a/web2/archive/whatis-web-20.html. Accessed 24 July 2018.

'PARK(ing) Day'. 2016. Accessed from http://parkingday.org.

Pierce, Melissa. 2010. Life in perpetual beta. Kickstarter. https://www.kickstarter.com/projects/ melissapierce/life-in-perpetual-beta/description. Accessed 24 July 2018.

Ratti, Carlo. 2015. Become smarter by streching-Not increasing-Your infrastrcture. Smart City Council. https://na.smartcitiescouncil.com/article/become-smarter-stretching-notincreasing-your-infrastructure.

Richert, E.D., and M. Lamping. 1998. Ebenezer howard and the garden city. Journal of the American Planning Association 64 (2): 125-127.

Sarkissian, Wendy, Nancy Hofer, Yollana Shore, Steph Vajda, and Cathy Wilkinson. 2009. Kitchen table sustainability: Practical recipes for community engagement with sustainability. London: Earthscan.

Sassen, Saskia. 2015. Urbanizing Technology. In Citizen's right to the digital city: Urban interfaces, activism, and placemaking, ed. Marcus Foth, Martin Brynskov, and Timo Ojala, 253-256. Singapore: Springer.

Schroeter, Ronald. 2012. Engaging new digital locals with interactive urban screens to collaboratively improve the city. In Proceedings of the ACM 2012 conference on computer supported cooperative work. New York: ACM. 
Schroeter, Ronald, and Marcus Foth. 2009. Discussions in space. In Proceedings of the 21st annual conference of the Australian computer-human interaction special interest group. Melbourne: ACM.

Schroeter, Ronald, and Kirralie Houghton. 2011. Neo-planning: Location-based social media to engage Australia's new digital locals. Australian Planner 48 (3): 191-202.

Shepard, Mark, and Antonina Simeti. 2013. What's so smart about the smart citizen. In Smart citizens, ed. Drew Hemment and Anthony Townsend, 13-18. Manchester: Future Everything Publications.

Shonfield, Katherine. 2000. Walls have feelings: Architecture, film and the city. London; New York: Routledge.

Tomitsch, Martin. 2014. Towards the real-time city: An investigation of public displays for behaviour change and sustainable living. In 7th making cities livable conference. Kingscliff.

Tomitsch, Martin, and M. Hank Haeusler. 2015. Infostructures: Towards a complementary approach for solving urban challenges through digital technologies. Journal of Urban Technology 22 (3): $37-53$.

Tomitsch, Martin, M. Ian McArthur, Hank Haeusler, and Marcus Foth. 2015. The role of digital screens in urban life: New opportunities for placemaking. In Citizen's right to the digital city, ed. Marcus Foth, Marti Brynskov, and Timo Ojala, 37-54. Singapore: Springer.

Weiser, Mark. 1993. Ubiquitous computing. Computer 26 (10): 71-72.

Joel Fredericks is a Postdoctoral Research Fellow in the School of Software at the University of Technology Sydney. His research sits across the domains of community engagement, urban planning, digital placemaking, media architecture and smart cities. He has worked on a variety of transdisciplinary research projects that adopt human-computer interaction and participatory design approaches to enable collaborative city-making. He has authored and co-authored many publications in journals, edited books and conference proceedings.

Glenda Amayo Caldwell is a Senior Lecturer in Architecture, School of Design, Creative Industries Faculty at the Queensland University of Technology. She leads the Design for Communities and Resilient Futures Research Program in the QUT Design Lab. Embracing transdisciplinary approaches from architecture, interaction design, human-computer interaction and robotics, she explores the intersection and translation of physical and digital media in creative processes. She is the author of numerous publications in the areas of Community Engagement, Media Architecture and Design Robotics. Her research has informed policy development, urban master plans and the adoption of design-led manufacturing capabilities in Queensland. She is an active researcher in the Urban Informatics and the Design Robotics research groups at QUT.

Marcus Foth is Professor of Urban Informatics in the QUT Design Lab, Creative Industries Faculty at the Queensland University of Technology. He is also an Honorary Professor in the School of Communication and Culture at Aarhus University, Denmark. His research brings together people, place and technology. His transdisciplinary work is at the international forefront of humancomputer interaction research and development with a focus on smart cities, community engagement, media architecture, Internet studies, ubiquitous computing and sustainability. He founded the Urban Informatics Research Lab in 2006 and the QUT Design Lab in 2016. In 2017, the Australian Computer Society (ACS) made him a fellow for "a sustained and distinguished contribution to the field of computer science. He is the international thought leader who coined the term urban informatics - now adopted by universities and industry worldwide. His work makes clear how academic research can successfully respond to societal challenges". 
Martin Tomitsch is a Chair of Design at the University of Sydney School of Architecture, Design and Planning and Director of the Design Lab, a research group that focuses on interaction design and design innovation. He is the Founding Member of the Austrian Network for Information and Communication Technologies for Development (ICT4D.at), the Media Architecture Institute (mediaarchitecture.org), state Co-chair of the Australian Computer-Human Interaction Special Interest Group (CHISIG), Visiting Lecturer at the Vienna University of Technology's Research Group for Industrial Software (INSO) and Visiting Professor at the Central Academy of Fine Arts, Beijing. His research sits across the domains of interaction design, creative technologies and cities and explores the role of design for improving the experience and lives of people.

Open Access This chapter is licensed under the terms of the Creative Commons Attribution 4.0 International License (http://creativecommons.org/licenses/by/4.0/), which permits use, sharing, adaptation, distribution and reproduction in any medium or format, as long as you give appropriate credit to the original author(s) and the source, provide a link to the Creative Commons license and indicate if changes were made.

The images or other third party material in this chapter are included in the chapter's Creative Commons license, unless indicated otherwise in a credit line to the material. If material is not included in the chapter's Creative Commons license and your intended use is not permitted by statutory regulation or exceeds the permitted use, you will need to obtain permission directly from the copyright holder.

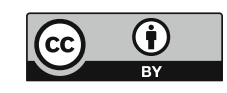

